\title{
Evaluation of the Accuracy of Trigger Finger Injection Using Ultrasound
}

\author{
Abd Elhakim Abd Allah Massoud ${ }^{1}$, Amro Ahmed Fouaad', Mohamed M Abdelkareem², \\ Ahmed Mohamed Ali El Baqary ${ }^{1}$
}

${ }^{1}$ Department of Orthopedic Surgery, ${ }^{2}$ Department of Rheumatology, Physical Medicine, Rehabilitation, Faculty of Medicine, Al-Azhar university, Cairo

Corresponding author: Ahmed Mohamed Ali El Baqary, Mobile: 01064262658; Email: orthopaedic.surgeon2016@gmail.com

\begin{abstract}
Background: Trigger finger is a common cause of disability and pain in the hand and The lines of management of this disease start by conservative treatment as rest, NSAID, local corticosteroid injection under the tendon sheath either blind or by musculoskeletal ultrasound guidance and surgery may indicated in recurrent cases.

Aim of the study: The aim of the present study was to evaluate the musculoskeletal ultrasound accuracy to guide the injection of corticosteroid in trigger finger management.

Material and methods: 50 cases that complaint from symptoms of trigger digit in this randomized, prospective control study were recorded. All the cases were injected by $1 \mathrm{ml}$ corticosteroid $1 \mathrm{ml}$ of $2 \%$ lidocaine at the level of the A1 pulley under the tendon sheath. The injection done under control of musculoskeletal ultrasound after a blinded needle insertion. Comorbidities and associated diseases were recorded. Follow up examinations at the 2 week and 6 months, no complications were recorded. The results were assessed according to the green's grading. The pain was assessed according to visual analogue scale.

Results: The cases in the present study were assessed according to age, associated diseases and hand dominance. The female patients were more than male patients in the present study. The injection under control of musculoskeletal ultrasound accurate more than a blinded injection even when an expert physician who did it. And It showed the same efficacy according to green's grading at the period of follow up examinations when compared with the pre-injection status. No complications were seen during the period of the follow up.

Conclusion: A different technique of injection using musculoskeletal ultrasound guidance all of which gave excellent accuracy superior to a blinded injection even when it is done by expert physician. However, the post injection result was similar to that of a blinded injection. Level one of evidence (randomized prospective study).

Keywords: Ultrasound -Trigger finger- Corticosteroid injection

\section{INTRODUCTION}

Trigger digit is a common hand problem ${ }^{(1)}$. The pathology in the A1 pulley in the form of thickening, which lead to clicking with movement, painful triggering and proximal interphalangeal joint contracture $^{(2)}$.

Ultrasound findings of trigger digit may include synovial sheath effusion with changes in the shape during movement, diffuse thickening which appear as

hypoechoic of the A1 pulley and tendon swelling ${ }^{(3)}$.

The tendon loses its normal smooth gliding surface at the pulley system. The A1 pulley is the most commonly level affected. It is more in females than in males ${ }^{(4,5,6)}$ with the highest involvement in the thumb ${ }^{(4,6,7)}$. The incidence of lifetime risk in normal population to develop trigger digit is between 2.5 to $3.5 \%$ and $10 \%$ with diabetics ${ }^{(8,9)}$.
\end{abstract}


In the management of such cases, the conservative and surgical options are allowed for treatment of trigger digit. Conservative treatment includes extension splint, icepacking, NSAID, corticosteroid injection and physiotherapy ${ }^{(10,11)}$.

Howard et al In $1953^{(12)}$ stated that the effective treatment of trigger finger was steroid injection into the flexural sheath. Advantages include low complication rate, ease of administration, office setting applicability, low morbidity and low cost ${ }^{(13}$, 14, 15).

The mechanism of corticosteroids action is not exactly known. It may be the anti-inflammatory effect, which reduces the swelling at the A1 pulley, but in the previous studies, the variation in efficacy rates was stated $^{(2)}$.

Tara's and his colleagues ${ }^{(16)}$ found that corticosteroid injection without ultrasound delivered true intra-sheath injections in only $37 \%$ of patients.

Lee and his colleagues ${ }^{(17)}$ found that ultrasound-guided steroid injection improved the accuracy of true intra-sheath injections to $70 \%$ However, a recent investigation found no difference in the success of treatment between intrasheath or extra-sheath corticosteroid injection. Therefore, the need to use ultrasound to guide the injection remains unclear ${ }^{(18,19)}$. As it was difficult to obtain accurate, intra flexural sheath injection so the accurate technique of injection through ultrasound guidance, gave better results, especially in some situation as in anatomically difficult location or disturbed anatomy and avoiding iatrogenic rupture or piercing of the tendon ${ }^{(21)}$.

Baumgarten et al. ${ }^{(20)}$ reported that the resolution of the symptoms after injection of trigger finger occur however definitive proof of accurate injection did not obtain in a randomized prospective study.

The present study aimed to estimate the accuracy of musculoskeletal ultrasoundguided steroid injection in management of trigger finger and whether the musculoskeletal ultrasound to be more accurate than a blinded injection even when expert physician do it.

The hypothesis of the present study was that the accuracy of musculoskeletal ultrasound-guided corticosteroid injection has superiority over the accuracy of a blinded injection even when done by expert physician.

\section{PATIENTS AND METHODS Search Strategy}

Fifty cases with trigger finger were injected over the period between March 2018 and July 2018, A prospective study was undertaken to evaluate the accuracy of trigger finger injection using ultrasound. The study was approved by the Ethics Board of AlAzhar University.

The cases were selected from AlAzhar University Orthopedics Outpatient Clinic and case selection was according to:

\section{The inclusion criteria:}

-Pain and tenderness at the position of A1 pulley.

-Pain and discomfort when flexing and extending the finger.

-Nodule palpation.

-Presence of a clicking sound with flexion or extension of the thumb.

-Snapping or locking of finger.

-Both sexes, All fingers and age group from 20 to 80 years old.

\section{The exclusion criteria:}

-Patients who had other hand conditions or degenerative joint disease.

-Patients who benefitted from other conservative treatment methods such as NSAID or rest.

-Patients who underwent surgical release.

-Recurrent cases were excluded from this study.

\section{Technique of Injection:}

The patients were transferred after clinical examination to the musculoskeletal ultrasound injection room and placed in setting position face to face with the physician during injection. The 
musculoskeletal ultrasound machine was positioned on the side of patient. All patients are evaluated using musculoskeletal ultrasound machine by a linear probe (7-18) MHZ, Aplio 400, Toshiba, Japan.

Musculoskeletal ultrasound is used at the beginning to ensure the diagnosis of trigger finger. We typically identify the flexor tendons in a longitudinal ultrasound view noting any abnormalities at A1 pulley such as tendon nodules or thickening of the pulley and assess its function clinically by examination of the patient through flexion and extension of the finger. The skin of the affected hand proximal to the transducer was prepared by $70 \%$ isopropyl alcohol. We are careful to maintain a sterile field around the edge of the transducer. Because we do not use a sterile transducer cover, the needle and puncture site are never allowed to contact the ultrasound transducer and using sterile gel (figure 1,2).

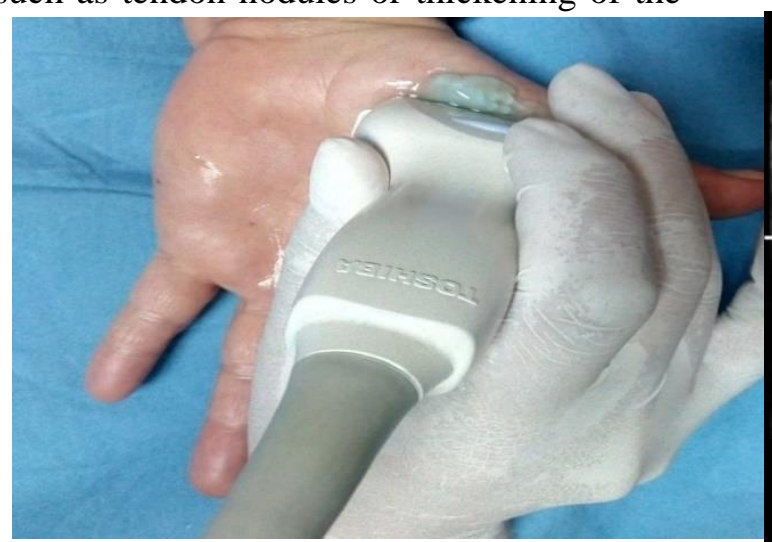

Fig. (1): Confirmation of trigger finger by

MSUS (the figure from the present study).

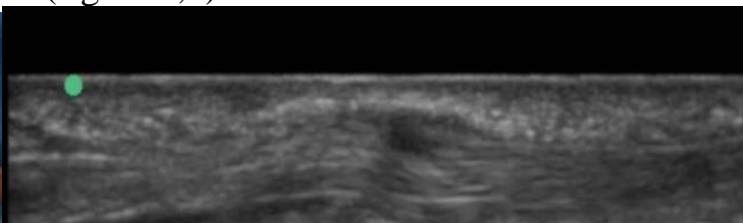

Trigger thumb - bunching flexor tendor under the A1 pulley
Fig. (2): Confirmation of trigger finger by

MSUS (the figure from the present study).

Then, a blinded needle insertion was done by the expert physician from proximal to distal at the nodule site then ultrasound used to confirm the site of the needle if intra-sheath or extrasheath and to guide the injection (figure 3,4 ).

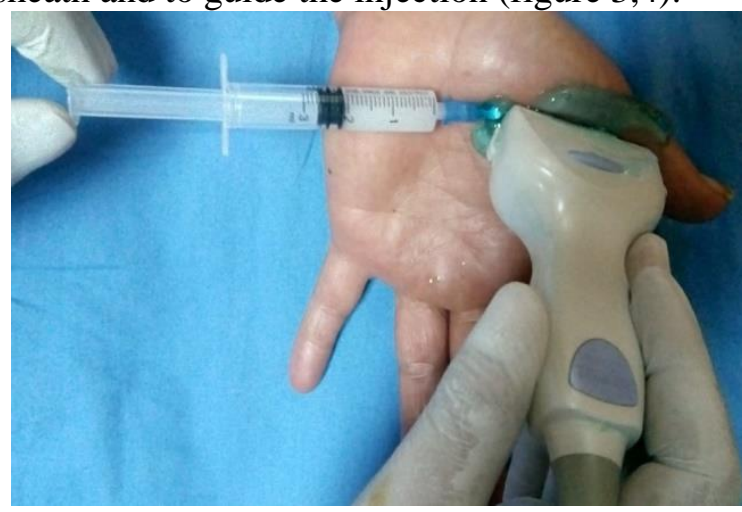

Fig. (3): Ultrasound used to confirm and to guide the site of the needle during injection (the figure from our study).

On the ultrasound view, the hypoechoic area represents the A1 pulley overlying the flexor digitorum profundus, flexor digitorum superficialis tendons and volar plate, in the

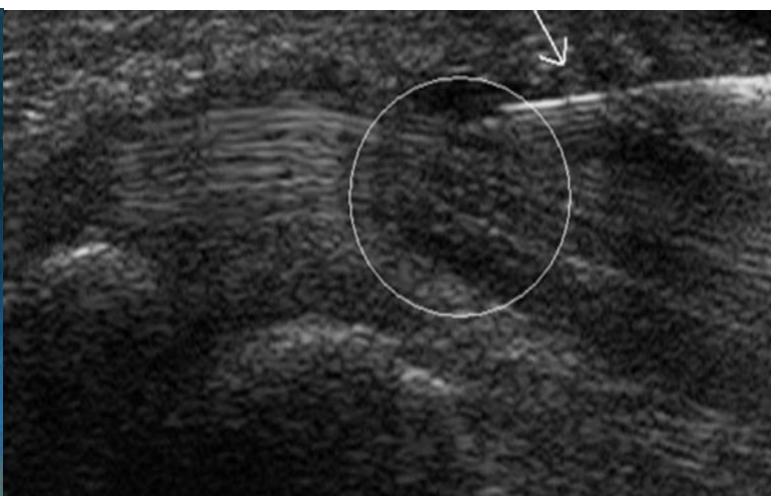

Fig. (4): The site of the needle in the region of thickening of the A1 pulley during an infiltration. The needle is coming from the right upper side, marked with an arrow (the figure from our study).

thumb. The A1 pulley has tendon of the flexor pollicis longus. Our target for injection intra flexural sheath at A1 pulley in longitudinal ultrasound views. 
We used a proximal-to-distal approach. We used needle with a 30 -gauge

and $1 \mathrm{ml}$ of corticosteroid mixed with $1 \mathrm{ml}$ of $2 \%$ lidocaine. The needle was directed to the site of injection. When the tip of the needle is within the target point, we start the injection. We visualized the flow of the injected solution under the A1 pulley by musculoskeletal ultrasound. If the flow was outside or no flow under the A1 pulley, we move the needle under control of musculoskeletal ultrasound guidance until the flow was obtained. The pulley may be tough to penetrated leading to obstruction of the needle and requiring insertion of largergauge needle. Then a small sterile adhesive dressing is applied, and the patient may resume activities as tolerated.

We found that it was technically more difficult to inject the thumb because of its oblique axis, orientation toward the palm of the hand, and smaller and rounder profile of the pulley, making it harder to visualize and approach the target. We found that it was easier if an assistant held the thumb in extension.

\section{After Injection}

Post Injection the patient was prescribed NSAIDS and antiedematous for 2 days. The patient is reviewed 2 weeks and then monthly post injection till 6 months. Follow up included patient satisfaction, recurrence and motor power of the involved digit.

\section{RESULTS}

We had 50 cases in our study, (31-60 years old) with mean age of 42.5 years old, $10 \%$ male, and $90 \%$ female most of them were grade 3 according to green's classification. In $66 \%$ the involved digit was in the dominant hand, $58 \%$ of the patient were diabetic, $40 \%$ the thumb was affected, $12 \%$ with multiple finger affection, $50 \%$ of the patients were complaining for (6-9 months) and all cases were managed by ultrasound-guided corticosteroid injection.

Table (1): Summary of studied patient's data.
During injection sitting, we compared the accuracy of a blinded needle insertion by expert physician and the accuracy of ultrasound-guided insertion of the needle and injection. All the cases had accurate ultrasound guided injection. All the cases had accurate blinded needle insertion except $15(30 \%)$ cases were extra sheath insertion of the needle and ultrasound-guided correction for these cases was done.

The patients were reviewed 2 weeks, and then monthly up to 6 months after the procedure. During each visit, the patient was asked about any signs of recurrence, infection or numbness. During each visit, the patient is examined as regards the motor power of the involved digit. None of the patients developed local site infection. None of the patients complained of numbness during the 6 months follow up period. None of the patients complained of recurrence in the 6 months follow up period, which is a relatively short period to judge recurrence. Patient satisfaction score was calculated after the 6 months follow up period.

\section{Patient satisfaction score}

Time to return to work and normal activity the score was given from 1 to 3 according to (a) 1 week was given score 3 (b) 1-2 weeks was given score 2 (c) More than 2 weeks was given score 1. Pain on a scale from $0-10$. The score was given from 1 to 3 according to (a) 1-3 was given score 3(b) 3-7 was given score 2 (c) 7-10 was given score 1 . Motor power of the affected digit, The score was given from 1 or 2 according to (a) like the rest of the non affected digits was given score 2 (b) Less than the rest of the non affected digit was given score $1^{(22)}$.

The maximum score that can be given was 8 (1) Patient score from 7-8 was regarded excellent (2) Patients score from 4-6 was regarded fair (3) Patients score from 1-3 was regarded poor ${ }^{(22)}$. In the present study, 30 patients out of the 50 scored from 7 to 8 (excellent), 15 patients out of the 50 scored from 4 to 6 (fair) and 5 patient out of the 50 scored from 1-3 (poor) as shown in see table (2) . 


\begin{tabular}{|c|c|c|c|c|c|c|c|c|}
\hline No. & Age & Sex & Finger & $\begin{array}{c}\text { Medical } \\
\text { Comorbidity }\end{array}$ & Dominance & Duration & Grade & Complications \\
\hline 1 & 45 & $\mathrm{~F}$ & Lt Middle & DM & $\mathrm{Rt}$ & 7 Months & 3 & $\ldots$ \\
\hline 2 & 48 & $\mathrm{~F}$ & Rt Thumb & & $\mathrm{Rt}$ & 9 Months & 4 & - \\
\hline 3 & 57 & $\mathrm{~F}$ & Lt thumb & DM & $\mathrm{Rt}$ & 6 Months & 3 & - \\
\hline 4 & 50 & $\mathrm{M}$ & Lt Ring & DM & $\mathrm{Lt}$ & 1 year & 3 & _ \\
\hline 5 & 40 & $\mathrm{~F}$ & Rt Thumb & $\ldots$ & RT & 1 year & 2 & - \\
\hline 6 & 59 & $\mathrm{~F}$ & Rt Thumb & & $\mathrm{Rt}$ & 6 Months & 3 & - \\
\hline 7 & 49 & $\bar{F}$ & Rt middle & $\overline{\mathrm{DM}}$ & RT & 6 Months & 3 & - \\
\hline 8 & 42 & $\mathrm{~F}$ & Rt Thumb & & $\mathrm{Rt}$ & 8 Months & 4 & - \\
\hline 9 & 44 & $\mathrm{~F}$ & Lt Thumb & DM & $\mathrm{Rt}$ & 6 Months & 3 & _- \\
\hline 10 & 40 & $\mathrm{~F}$ & Rt Thumb & & $\mathrm{Rt}$ & 7 Months & 3 & $=$ \\
\hline 11 & 52 & $\mathrm{~F}$ & Rt Thumb & & $\mathrm{Rt}$ & 9 Months & 2 & _ \\
\hline 12 & 43 & $\mathrm{~F}$ & Lt Middle & DM & $\mathrm{Rt}$ & 6 Months & 3 & $\ldots$ \\
\hline 13 & 37 & $\mathrm{~F}$ & Rt Middle & & $\mathrm{Rt}$ & 1.5 Years & 3 & - \\
\hline 14 & 41 & $\mathrm{~F}$ & Lt Ring & DM & $\mathrm{Rt}$ & 1 Year & 4 & _ \\
\hline 15 & 45 & $\mathrm{~F}$ & Lt Middle & DM & $\mathrm{Rt}$ & 10 months & 3 & - \\
\hline 16 & 50 & $\mathrm{~F}$ & Lt Index & DM & $\mathrm{Lt}$ & 1 Year & 2 & _- \\
\hline 17 & 45 & $\mathrm{~F}$ & Lt Thumb & & $\mathrm{Rt}$ & 1 year & 3 & _ \\
\hline 18 & 33 & $\mathrm{~F}$ & Rt Thumb & DM & $\mathrm{Rt}$ & 6 Months & 3 & - \\
\hline 19 & 53 & $\mathrm{M}$ & RT Ring & & $\mathrm{Rt}$ & 3 Years & 4 & - \\
\hline 20 & 60 & $\mathrm{~F}$ & Rt Middle & DM & $\mathrm{Rt}$ & 1 Year & 3 & _- \\
\hline 21 & 54 & $\mathrm{~F}$ & Rt Ring & DM & $\mathrm{Rt}$ & 1 year & 3 & _ \\
\hline 22 & 50 & $\mathrm{~F}$ & Lt Index & DM & $\mathrm{Rt}$ & 6 Months & 3 & - \\
\hline 23 & 45 & $\mathrm{~F}$ & Rt Thumb & & $\mathrm{Rt}$ & 8 Months & 4 & 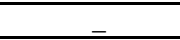 \\
\hline 24 & 42 & $\mathrm{~F}$ & Lt Ring & DM & $\mathrm{Rt}$ & 8 months & 3 & _ \\
\hline 25 & 39 & $\mathrm{~F}$ & Rt Ring & DM & $\mathrm{Rt}$ & 1 year & 3 & - \\
\hline 26 & 54 & $\mathrm{~F}$ & Rt Thumb & & $\mathrm{Rt}$ & 11 Months & 3 & _ \\
\hline 27 & 53 & $\bar{M}$ & Lt Thumb & $\overline{\mathrm{DM}}$ & $\mathrm{Rt}$ & 19 Months & 4 & 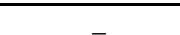 \\
\hline 28 & 47 & $\mathrm{~F}$ & Rt Middle & DM & $\mathrm{Rt}$ & 6 Months & 3 & - \\
\hline 29 & 52 & $\mathrm{~F}$ & Rt Middle & & $\mathrm{Rt}$ & 11 Months & 3 & _ \\
\hline 30 & 51 & $\mathrm{~F}$ & Lt Ring & DM & $\mathrm{Lt}$ & 2 years & 2 & _ \\
\hline 31 & 44 & $\mathrm{~F}$ & Rt Ring & DM & $\mathrm{Rt}$ & 6 Months & 3 & - \\
\hline 32 & 45 & $\mathrm{~F}$ & Lt Middle & DM & $\mathrm{Rt}$ & 7 Months & 3 & - \\
\hline 33 & 38 & $\mathrm{M}$ & Rt Ring & $\ldots$ & $\mathrm{Rt}$ & 8 Months & 4 & - \\
\hline 34 & 55 & $\mathrm{~F}$ & Lt Thumb & & $\mathrm{Rt}$ & 1 year & 3 & _- \\
\hline 35 & 43 & $\mathrm{~F}$ & Rt Ring & $\mathrm{DM}$ & RT & 1 year & 2 & - \\
\hline 36 & 51 & $\mathrm{~F}$ & Rt Thumb & 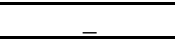 & $\mathrm{Rt}$ & 10 Months & 3 & - \\
\hline 37 & 41 & $\mathrm{~F}$ & Rt middle & DM & RT & 6 Months & 4 & \\
\hline 38 & 42 & $\mathrm{~F}$ & Rt Thumb & & $\mathrm{Rt}$ & 8 Months & 3 & - \\
\hline 39 & 50 & $F$ & Lt Ring & $\overline{D M}$ & $\mathrm{Rt}$ & 6 Months & 4 & 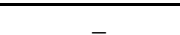 \\
\hline 40 & 39 & $\mathrm{~F}$ & Rt Thumb & - & $\mathrm{Rt}$ & 7 Months & 3 & - \\
\hline 41 & 57 & $\mathrm{~F}$ & Rt Thumb & & $\mathrm{Rt}$ & 1.5 years & 4 & - \\
\hline 42 & 45 & $\mathrm{~F}$ & Lt Ring & DM & $\mathrm{Rt}$ & 6 Months & 3 & - \\
\hline 43 & 42 & $\mathrm{~F}$ & Rt Middle & & $\mathrm{Rt}$ & 10 Months & 3 & \\
\hline 44 & 43 & $\mathrm{~F}$ & Lt Ring & DM & $\mathrm{Rt}$ & 1 Year & 4 & - \\
\hline 45 & 41 & $\mathrm{~F}$ & Rt Middle & DM & $\mathrm{Rt}$ & 2 Years & 3 & - \\
\hline 46 & 42 & $\mathrm{~F}$ & Lt Ring & DM & $\mathrm{Rt}$ & 1 Year & 4 & - \\
\hline 47 & 45 & $\mathrm{~F}$ & Lt Thumb & & $\mathrm{Rt}$ & 2 years & 4 & _ \\
\hline 48 & 31 & $\mathrm{~F}$ & Rt Thumb & DM & $\mathrm{Rt}$ & 6 Months & 3 & 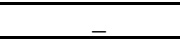 \\
\hline 49 & 54 & $\mathrm{M}$ & RT Ring & & $\mathrm{Rt}$ & 3 Years & 4 & \\
\hline 50 & 45 & $\mathrm{~F}$ & Rt Middle & DM & $\mathrm{Rt}$ & 1 Year & 4 & _ \\
\hline
\end{tabular}

\section{Patient satisfaction score}

Time to return to work and normal activity the score was given from 1 to 3 according to (a) 1 week was given score 3 (b) 1-2 weeks was given score 2 (c) More than 2 weeks was given score 1 . Pain on a scale from $0-10$. The score was given from 1 to 3 according to (a) 1-3 was given score 3(b) 3-7 was given score 2 (c) 7-10 was given score 1 . Motor power of the affected digit, The score was given from 1 or 2 according to (a) like the rest of the non affected digits was given score 2 (b) Less than the rest of the non affected digit was given score $1^{(22)}$. 
The maximum score that can be given was 8 (1) Patient score from 7-8 was regarded excellent (2) Patients score from 4-6 was regarded fair (3) Patients score from 1-3 was regarded poor ${ }^{(22)}$. In the present study, 30 patients out of the 50 scored from 7 to 8 (excellent), 15 patients out of the 50 scored from 4 to 6 (fair) and 5 patient out of the 50 scored from 1-3 (poor) as shown in see table (2) .

(Table 2): Summary of studied patient's complication and satisfaction.

\begin{tabular}{|l|l|l|l|l|l|l|}
\hline $\begin{array}{l}\text { Number of } \\
\text { cases }\end{array}$ & $\begin{array}{l}\text { Complication as } \\
\text { (paresthesia, } \\
\text { infection, } \\
\text { recurrence) }\end{array}$ & $\begin{array}{l}\text { Score for } \\
\text { return to } \\
\text { activity }\end{array}$ & $\begin{array}{l}\text { Score } \\
\text { for pain }\end{array}$ & $\begin{array}{l}\text { Score for } \\
\text { motor } \\
\text { power }\end{array}$ & $\begin{array}{l}\text { Total } \\
\text { score }\end{array}$ & $\begin{array}{l}\text { Patient } \\
\text { satisfaction }\end{array}$ \\
\hline $\begin{array}{l}30 \text { out of the } \\
50 \text { cases }\end{array}$ & No & 3 & 3 & 2 & 8 & Excellent \\
\hline $\begin{array}{l}15 \text { out of the } \\
50 \text { cases }\end{array}$ & No & 2 & 2 & 2 & 6 & Fair \\
\hline $\begin{array}{l}5 \text { out of the } \\
50 \text { cases }\end{array}$ & No & 1 & 1 & 1 & 3 & Poor \\
\hline
\end{tabular}

\section{DISCUSSION}

This study showed that trigger finger is a common condition that affects females more than males, as 45 out of the 50 patients in the random sample were females $(90 \%)$.

The results demonstrated that diabetes mellitus is closely related to the development of trigger finger and affection of multiple fingers was seen only in diabetic patients and this was observed in 6 patients of the study group.

Local corticosteroid injection in treatment of trigger finger is considered the first-line. The injection was done into the tendon sheath; it is technically difficult so ultrasound was used to guide the injection.

The important finding in our study was that ultrasound-guided injection had a superiority as regard the accuracy but with the same benefits and efficacy compared to the blinded technique. This study showed the advantages of ultrasound-guided injection as it's the most accurate, safe and effective method for management of trigger finger regardless the clinical grade. None of the patients experienced the problem of recurrence within the 6 months follow up period. $90 \%$ of the patients were satisfied with the ultrasound guided injection and none of them complained of a weak motor power of the involved digit in the 6 months follow up period.

All these randomized trials clinically suffered from the performance bias due to that we could not be blinded during the procedure that we were performing.

Finally, the size of the sample was small, with a short follow up period, so the findings of our study could not to be generalized. The strengths of our study were its prospective design rather than adequate power and $95 \%$ success rate in the follow-up evaluation.

These results can be compared to the results of several other studies conducted before.

Bodor and Flossman (23) and Callegri et al. (24) reported that using ultrasound to guide the injection decreased the complications as the risk of iatrogenic injuries (tendon rupture and tendon piercing) and better results were reported.

Dala-Ali et al. ${ }^{(25)}$ reported that the efficacy of corticosteroid injection by a blinded technique was $66 \%$ in a retrospective study. Shakeel and Ahmad ${ }^{(26)}$ reported that the efficacy after a blinded injection was $70 \%$ in a randomized, prospective, control study. Baumgarten et al. ${ }^{(27)}$. reported that the cure rate after corticosteroid injection was $86 \%$ in a prospective study. Marks and Gunther ${ }^{(28)}$ stated that the efficacy of injection of steroid in the management of trigger thumbs was 97 $\%$. The efficacy means recovery of the pain and triggering. Akhtar and Burke ${ }^{(29)}$ stated that the higher cure rate is related to some factors as single digit involvement, female 
population and the experience needed from the physician.

Previous studies give us an idea about the wide range of cure rates after steroid injection because of the comorbidities (rheumatoid arthritis, DM), psychosocial factors, the severity, nodule formation, the

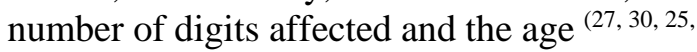
31,32).

Bodor and Flossman ${ }^{(23)}$ stated that the minimally invasive and highly effective management for treatment of trigger finger with a $94 \%$ success rate at 6 months was corticosteroid injection. Kazuki et al. (33) reported that the improvement of the pain in $98 \%$ of patients was after treatment by a blind injection in a randomized, prospective, study.

In our study, we found that the accuracy of injection using ultrasound guidance was $100 \%$, when compared to needle insertion by a blinded expert physician. which reached about $70 \%$, while the satisfaction after the injection was $90 \%$ with $10 \%$ of the patients needed surgical release.

Although there were no complications after corticosteroid injection, such as (tendon rupture, hypopigmentation, infection and atrophy of subcutaneous fat) were reported in the present study, except for a transient hyperglycemia after injection of corticosteroid that might occur as shown in a previous study ${ }^{(34)}$. However, blood glucose levels after injection was not checked in our study.

\section{CONCLUSION}

A different technique of injection using musculoskeletal ultrasound guidance all of which gave excellent accuracy superior to a blinded injection even when done by expert physician but the post injection result similar to that of a blinded injection. Ultrasound guided injection is accurate, safe, cheap and effective method and allows earlier return to normal activities with no recorded complication in our study and is now adopted as the standard technique in many orthopedic centers worldwide.

REFERENCES
1. Cakmak F, Wolf MB, Bruckner T, Hahn P, Unglaub F (2012): Follow-up investigation of open trigger digit release. Arch Ortho Trauma Surg., 132:685-691.

2. Wang J, Zhao JG, Liang CC (2013): Percutaneous release, open surgery, or corticosteroid injection, which is the best treatment method for trigger digits? Clin Ortho Relat Res., 471:1879-1886.

3. Serafini G, Derchi LE, Quadri $P$ et al. (1996): High-resolution sonography of the flexor tendons in trigger fingers. $\mathrm{J}$ Ultrasound Med., 15:213-219.

4. Akhtar S, Bradley MJ, Quinton DN, Burke FD (2005): Management and referral for trigger finger/thumb. BMJ., 331:30-3.

5. Flatt AE (2007): Notta's nodules and trigger digits. Proc (Bayl Univ MedCent), 20:143-5.

6. Moore JS (2000): Flexor tendon entrapment of the digits (trigger finger and trigger thumb). J Occup Environ Med., 42: 526-45.

7. Lange-Riess D, Schuh R, Hönle W, Schuh A (2009): Long-term results of surgical release of trigger finger and trigger thumb in adults. Arch Orthop Trauma Surg., 129:1617-9.

8. Akhtar S, Bradley MJ, Quinton DN, Burke FD (2005): Management and referral for trigger finger/thumb. BMJ., 331:30-33.

9. Dala-Ali BM, Nakhdjevani A, Lloyd MA, Schreuder FB (2012): The efficacy of steroid injection in the treatment of trigger finger. Clin Orthop Surg., 4:263268.

10. Murphy D, Failla JM, Koniuch MP, et al. (1995): Steroid versus placebo injection for trigger finger. J Hand Surg Am., 20:628-631.

11. Patel MR, and Bassini L (1992): Trigger fingers and thumb: when to splint, inject, or operate. J Hand Surg Am., 17:110-113.

12. Howard LD, Pratt DR, Bunnell $S$ (1953): The use of compound $\mathrm{F}$ (hydrocortone) in operative and nonoperative conditions of the 
hand. J Bone Joint Surg Am., 35:9941002.

13. Benson LS, and Ptaszek AJ (1997): Injection versus surgery in the treatment of trigger finger. J Hand Surg Am., 22:138-144.

14. Marks MR, and Gunther SF (1989): Efficacy of cortisone injection in treatment of trigger fingers and thumbs. $\mathrm{J}$ Hand Surg Am., 14:722-727.

15. Nimigan AS, Ross DC, Gan BS (2006): Steroid injections in the management of trigger fingers. Am $\mathbf{J}$ Phys Med Rehabil., 85:36-43.

16. Taras JS, Raphael JS, Pan WT, Movagharnia F, Sotereanos DG (1998): Corticosteroid injections for trigger digits: is intrasheath injection necessary? J Hand Surg Am., 23(4):717722.

17. Lee DH, Han SB, Park JW, Lee SH, Kim KW, Jeong WK (2011): Sonographically guided tendon sheath injections are more accurate than blind injections: implications for trigger finger treatment. J Ultrasound Med., 30(2):197203.

18. Cecen GS, Gulabi D, Saglam F, Tanju NU, Bekler HI (2015): Corticosteroid injection for trigger finger: blinded or ultrasound-guided injection? Arch Orthop Trauma Surg., 135(1):125-131.

19. 19.Shinomiya R, Sunagawa $T$, Nakashima Y,Yoshizuka M, Adachi N (2016): Impact of corticosteroid injection site on the treatment success rate of trigger finger: a prospective study comparing ultrasound-guided true intrasheath and true extra-sheath injections. Ultrasound Med Biol., 42(9):2203-2208.

20. Baumgarten KM, Gerlach $D$, Boyer MI (2007): Corticosteroid injection in diabetic patients with trigger finger. $\mathrm{J}$ Bone Joint Surg Am., 89:2604-2611.

21. Godey SK, Bhatti WA, Watson JS, et al. (2006): A technique for accurate and safe injection of steroid in trigger digits using ultrasound guidance. Acta Orthop Belg., 72:633-634.
22. Stahl S, Kanter Y, karnielli E (1997). Outcome of trigger finger treatment in diabetes. J Diabetes complicat, 11:28790.

23. Bodor $M$, and Flossman $T$ (2009): Ultrasound-guided first annular pulley injection for trigger finger. J Ultrasound Med., 28:737-743.

24. Callegari L, Spano E, Bini A, Valli F, Genovese E, Fugazzola C (2011): Ultrasound-guided injection of a corticosteroid and hyaluronic acid: a potential new approach to the treatment of trigger finger. Drugs R D., 11:137145.

25. Dala-Ali BM, Nakhdjevani A, Lloyd MA, Schreuder FB (2012): The efficacy of steroid injection in the treatment of trigger finger. Clin Orthop Surg., 4:263268.

26. Shakeel H, and Ahmad TS (2012): Steroid injection versus NSAID injection for trigger finger: a comparative study of early outcomes. J Hand Surg Am., 37:19-23.

27. Baumgarten KM, Gerlach $D$, Boyer MI (2007): Corticosteroid injection in diabetic patients with trigger finger. J Bone Joint Surg Am., 89:2604-2611.

28. Marks MR, and Gunther SF (1989): Efficacy of cortisone injection in treatment of trigger fingers and thumbs. $\mathbf{J}$ Hand Surg Am., 14:722-727.

29. Akhtar S, and Burke FD (2006): Study to outline the efficacy and illustrate techniques for steroid injection for trigger finger and thumb. Postgrad Med J., 82:763-766.

30. Brito JL, and Rozental TD (2010): Corticosteroid injection for idiopathic trigger finger. J Hand Surg Am., 35:831833.

31. Julka A, Vranceanu AM, Shah AS, Peters F, Ring D (2012): Predictors of pain during and the day after corticosteroid injection for idiopathic trigger finger. J Hand Surg Am., 37:237242.

32. Rozental TD, Zurakowski D, Blazar PE (2008): Trigger finger: prognostic indicators of recurrence following 
corticosteroid injection. J Bone Joint Surg Am., 90:1665-1672.
33. Kazuki K, Egi T, Okada M, Takaoka K (2006): Clinical outcome of extra synovial steroid injection for trigger finger. Hand Surg., 11:1-4.

34. Wang AA, and Hutchinson DT (2006): The effect of corticosteroid injection for trigger finger on blood glucose level in diabetic patients. J Hand Surg Am., 31:979-981. 